\title{
Toward Improved Cloud-Phase Simulation with a Mineral Dust and Temperature-Dependent Parameterization for Ice Nucleation in Mixed-Phase Clouds
}

\author{
Songmiao Fan, Paul Ginoux, Charles J. Seman, Levi G. Silvers, and Ming Zhao \\ NOAA/Geophysical Fluid Dynamics Laboratory, Princeton, New Jersey
}

(Manuscript received 24 September 2018, in final form 14 August 2019)

\begin{abstract}
Mixed-phase clouds are frequently observed in the atmosphere. Here we present a parameterization for ice crystal concentration and ice nucleation rate based on parcel model simulations for mixed-phase stratocumulus clouds, as a complement to a previous parameterization for stratus clouds. The parcel model uses a singular (time independent) description for deposition nucleation and a time-dependent description for condensation nucleation and immersion freezing on mineral dust particles. The mineral dust and temperature-dependent parameterizations have been implemented in the Geophysical Fluid Dynamics Laboratory atmosphere model, version 4.0 (AM4.0) (new), while the standard AM4.0 (original) uses a temperature-dependent parameterization. Model simulations with the new and original AM4.0 show significant changes in cloud properties and radiative effects. In comparison to measurements, cloud-phase (i.e., liquid and ice partitioning) simulation appears to be improved in the new AM4.0. More supercooled liquid cloud is predicted in the new model, it is sustained even at temperatures lower than $-25^{\circ} \mathrm{C}$ unlike in the original model. A more accurate accounting of ice nucleating particles and ice crystals is essential for improved cloud-phase simulation in the global atmosphere.
\end{abstract}

\section{Introduction}

Widespread temperature inversions and low temperatures in the Arctic promote the formation of mixedphase stratocumulus, resulting in high albedos for shortwave radiation and "greenhouse" trapping of longwave radiation (e.g., Prenni et al. 2007; Morrison et al. 2012). Stratocumulus and altocumulus clouds are sustained by turbulence driven by cloud-top cooling and enhanced by latent heating at the liquid base (e.g., de Boer et al. 2010; Avramov et al. 2011; Fan et al. 2011; Solomon et al. 2011; Fridlind et al. 2012; Yang et al. 2013; Savre and Ekman 2015a; Fu and Xue 2017; Roesler et al. 2017; Fridlind and Ackerman 2018). The liquid water paths (LWP) of these clouds depend on the thermodynamic phase partition as well as the geometrical thickness. Ice nucleating particles (INPs), such as mineral dust, metal oxides and bacteria, have been observed to promote heterogeneous ice nucleation in Arctic clouds (e.g., Prenni et al. 2009; McFarquhar et al. 2011; Wilson et al. 2015). The rapid growth of ice

Corresponding author: Songmiao Fan, Songmiao.Fan@noaa.gov crystals via vapor deposition may cause subsaturation with respect to liquid water and droplet evaporation, known as the Wegener-Bergeron-Findeisen (WBF) process, which decreases LWP and cloud radiative effects (e.g., Korolev 2007; Fan et al. 2011; Tan et al. 2016).

Mixed-phase cloud is most studied in the Arctic, but it occurs in the rest of the globe and plays an important role in Earth's radiation budget (e.g., Matus and L'Ecuyer 2017). In particular, mixed-phase clouds are frequent over the Southern Ocean and Antarctica (e.g., Bodas-Salcedo et al. 2016; Jolly et al. 2018; Mace and Protat 2018). It was shown that global climate models that convert supercooled water to ice at relatively warm temperatures tend to have a greater mean-state cloud fraction and more negative cloud feedback in the middleand high-latitude Southern Hemisphere, which results from a tuning of cloud cover to compensate for biases in LWP in order to obtain a balance of radiation in the models (McCoy et al. 2016). An accurate representation of ice nucleation and mixed-phase clouds is essential not only for extending the range of numerical weather forecast but also for quantifying cloud feedbacks in future climate scenarios (Tan et al. 2016). 
Various parameterizations of ice nucleation, ice crystal concentration, and ice-liquid phase partitioning have been implemented in atmospheric models, resulting in a wide spread of results among climate models (Komurcu et al. 2014; Cesana et al. 2015). This study is intended to present a new parameterization for ice nucleation, which is based on previous laboratory experiments and evaluated with in situ aircraft measurements, in an effort to improve cloud-phase simulation in atmospheric models. In a previous study, Fan et al. (2017) presented parcelmodel simulations of mixed-phase stratus and stratocumulus clouds in comparison with aircraft measurements in the Arctic. Mineral dust aerosol is the only INP in this study. Parameterizations for ice crystal concentration $N_{i}$ and ice nucleation rate $J$ in stratus clouds were derived as functions of temperature $T$ and dust concentration ([dust]), including the effects of pressure $P$ and vertical velocity $w$. As a follow-up, this paper will present parameterizations for $N_{i}$ and $J$ in stratocumulus clouds, where a cellular convection is prescribed with an oscillating $w$, as functions of $T$ and [dust]. A modification to the parcel model is described in section 2. The parameterizations are presented in section 3 . The effects of the new parameterization for ice crystal concentration implemented in the Geophysical Fluid Dynamics Laboratory (GFDL) atmosphere model, version 4.0 (AM4.0), are described in section 4. A summary and conclusions are presented in section 5 .

\section{Model description}

The parcel model and simulations are described in Fan et al. (2017). Briefly, a vertical profile of $w$ is specified for updrafts and downdrafts (Fig. A1) based on a large-eddy simulation of stratocumulus (Solomon et al. 2011). Alternative vertical profiles of $w$ (Yang et al. 2013; Roesler et al. 2017) are also considered (Fig. A1), and different cloud thicknesses $(250,550,1150 \mathrm{~m})$ and maximum values of $w\left(0.5,1.0,1.5 \mathrm{~m} \mathrm{~s}^{-1}\right)$ are specified in sensitivity simulations. The parcel model calculates $P$ and $T$ as air moves up or down from an initial state while the parcel has no exchange of mass or energy with its environment. The model predicts relative humidity over ice (RHi) and over water (RHw) and droplet and ice crystal number concentrations and sizes.

The rate of heterogeneous ice nucleation is calculated on dust aerosols, which is distributed in 20 size bins (dry diameter $D=0.02-20 \mu \mathrm{m}$ ). The physics of ice nucleation is presently not well understood, and its description is either singular (i.e., time independent, deterministic) or time dependent (i.e., stochastic as in the classical nucleation theory) (e.g., Welti et al. 2012; Vali 2014). A mix of the two has also been suggested for the interpretation of laboratory experiments (Vali and Snider 2015). Here, a singular description is used for deposition nucleation and a time-dependent description for condensation and immersion freezing. The following descriptions are so chosen because they help improve prediction of ice crystal concentrations as compared to aircraft measurements (Fan et al. 2017, and unpublished results). In the singular description the activated fraction $f_{\text {ice }}$ is calculated for each size bin based on the surface area $A$ and density of active sites $n_{s}\left(\mathrm{~m}^{-2}\right)$ :

$$
\begin{aligned}
f_{\text {ice }} & =1-\exp \left(-A n_{s}\right), \\
n_{s} & =\exp (0.42 \mathrm{RHi}-30.7) .
\end{aligned}
$$

Equation (2) is an empirical relation given by the average of measurements at $-30^{\circ}$ and $-35^{\circ} \mathrm{C}$ for illite particles coated with sulfate (Kulkarni et al. 2014). Deposition nucleation is determined by the increase of RHi for each time step.

The time-dependent description is based on a relationship between the nucleation rate coefficient per unit INP surface area $J_{\text {het }}\left(\mathrm{cm}^{-2} \mathrm{~s}^{-1}\right)$ and water activity $a_{w}$ (Knopf and Alpert 2013; Alpert and Knopf 2016). In the $a_{w}$-based immersion freezing model (ABIFM), $J_{\text {het }}$ is calculated according to

$$
\begin{aligned}
\log _{10}\left(J_{\text {het }}\right) & =22.66\left[a_{w}(T)-a_{w, \text { ice }}(T)\right]-1.35, \\
a_{w, \text { ice }}(T) & =p_{\text {ice }}(T) / p_{w}(T),
\end{aligned}
$$

where $p_{\text {ice }}(T)$ and $p_{w}(T)$ are the saturation water vapor pressure of ice and pure liquid water at temperature $T$. The coefficients in Eq. (3) are derived based on experiments with natural dust particles (Niemand et al. 2012). The rate of condensation and immersion freezing is calculated using Eqs. (3) and (4) for each size bin based on total surface area, where $a_{w}$ is assumed equal to RHw. For RHi $>100 \%$ and RHw $<98 \%$ the larger increase is chosen between deposition nucleation and condensation nucleation. For RHi $>100 \%$ and RHw $>$ $98 \%$ immersion freezing only is allowed.

The time-dependent description for immersion freezing, ABIFM (Alpert and Knopf 2016), is derived based on many laboratory experiments with natural dust particles (Niemand et al. 2012). These laboratory measurements have recently been reanalyzed by Ullrich et al. (2017), who presented a new time-independent description that gives twice as many active sites but with similar temperature dependence. This update, if incorporated into the ABIFM, could increase $J_{\text {het }}$ by a factor of 2. The time-independent parameterization for deposition nucleation [Eqs. (1) and (2)] proposed 


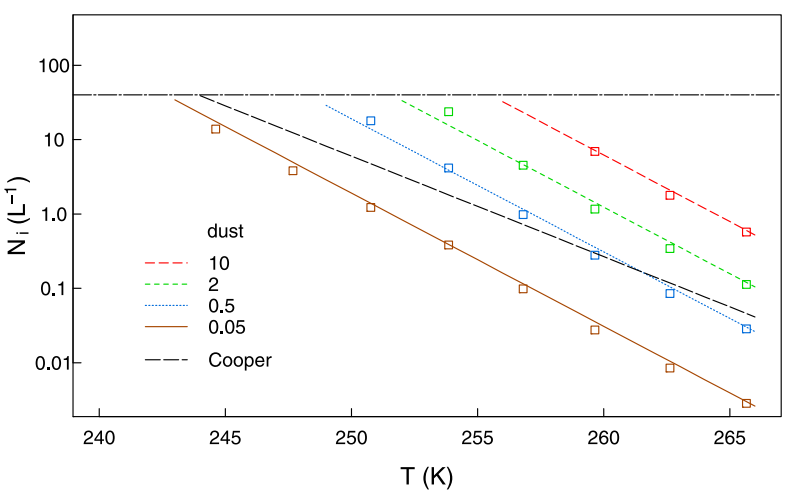

FIG. 1. Number concentration of ice crystals (time-weighted column average $N_{i}$ for $D<200 \mu \mathrm{m}$ ) in mixed-phase stratocumulus clouds as a function of average temperature. The symbols indicate results from individual parcel model simulations. The lines (see legend) indicate calculations using Eq. (5) for [dust] $=10,2,0.5$, and $0.05 \mu \mathrm{g} \mathrm{m}^{-3}$ and using Eq. (6) based on Cooper (1986).

by Kulkarni et al. (2014) for illite particles predicts substantially larger frozen fractions near $-35^{\circ} \mathrm{C}$ than that proposed by Ullrich et al. (2017) for natural dust particles.

It seems inconsistent to choose a time-dependent ice nucleation scheme for immersion freezing and a timeindependent scheme for deposition nucleation. Our choices in this study are largely empirical; multiple other schemes were less satisfactory when they were used to predict ice crystal number concentrations observed in the Arctic (results not shown). We speculate that deposition nucleation appears to be more deterministic because of rapid growth by vapor deposition once an ice embryo reaches certain critical size. By contrast, thermal molecular diffusion in the liquid phase is much slower, limiting the rate of growth of ice embryos during immersion freezing, which then tends to be more stochastic. Furthermore, the energy barrier (latent heat) to reverse deposition (sublimation) is greater than that to reverse freezing (melting). As a note of caution, it remains to be determined whether a time-dependent description is appropriate for immersion freezing (Vali 2014), even though a parcel model with the time-dependent ABIFM predicts well in situ measurements of ice crystal concentration in clouds at temperatures between $-10^{\circ}$ and $-40^{\circ} \mathrm{C}$ (Fan et al. 2017).

\section{Ice in stratocumulus}

Parcel model simulations were carried out for stratocumulus with initial $T$ between 244 and $268 \mathrm{~K}$ and initial $P$ of $950 \mathrm{hPa}$. Following the convention in previous studies (Morrison and Gettelman 2008; Thompson et al.2008), we choose to separate ice and snow particles

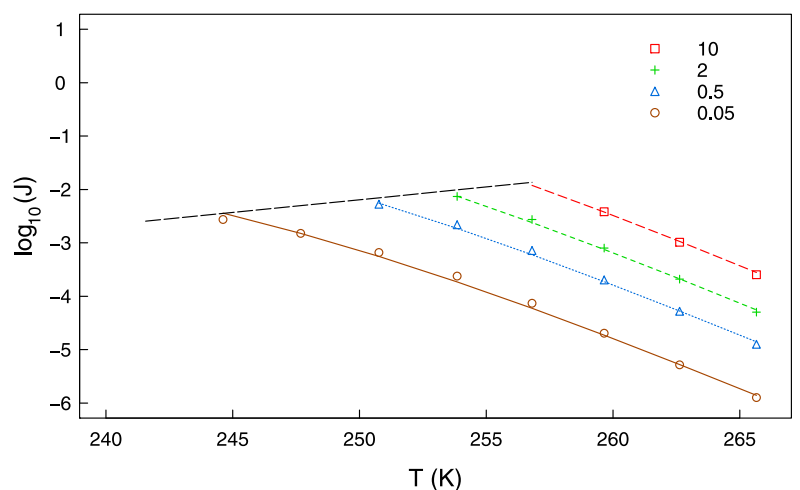

FIG. 2. Common log of the rate of ice nucleation (time-weighted column average $J ; \mathrm{L}^{-1} \mathrm{~s}^{-1}$ ) as a function average temperature. The symbols (see legend) indicate results from individual parcel model simulations. The lines indicate calculations using Eq. (7) for [dust] $=10,2,0.5$, and $0.05 \mu \mathrm{g} \mathrm{m}^{-3}$ and using Eq. (8) for the upper limit (long-dashed black line) below which mixed-phase stratocumulus clouds may be sustained.

at $D=200 \mu \mathrm{m}$. Figure 1 shows the mean concentrations of ice $(D<200 \mu \mathrm{m})$ as a function of column-average $T$ for initial [dust] $=0.05,0.5,2.0$, and $10.0 \mu \mathrm{g} \mathrm{m}^{-3}$, respectively. Results are omitted when the liquid phase is absent, which caps $N_{i}$ to about $40 \mathrm{~L}^{-1}$. This suggests that mixed-phase stratocumulus cannot be maintained with higher ice concentrations due to desiccation of air by ice growth. The parcel model results were compared in Fan et al. (2017) to aircraft measurements in the Arctic (McFarquhar et al. 2007; Avramov et al. 2011; Lloyd et al. 2015). It is found that dust concentrations observed in the Arctic are sufficient to sustain the observed ice crystal concentrations (Fan et al. 2017).

A least squares fit (shown by lines in Fig. 1) to the parcel model results (symbols) yields

$$
N_{i}=0.00274[\text { dust }] e^{0.412(273.16-T)},
$$

where [dust] is mass concentration $\left(\mu \mathrm{g} \mathrm{m}^{-3}\right)$. The model results and fitted lines may be compared to a widely used empirical relation (long-dashed black line) based on measurements in cap clouds and orographic clouds (Cooper 1986):

$$
N_{i}=0.00447 e^{0.311(273.16-T)} .
$$

The model results have stronger temperature dependence than the Cooper line as well as a linear dependence on [dust]. Note that Eq. (5) is derived from simulations with an initial (base) pressure of $950 \mathrm{hPa}$, the value of $N_{i}$ at an arbitrary base pressure $P$ should be scaled by a factor of $P / 950$ (see. Fig. A7).

Figure 2 shows the time-averaged rates of immersion freezing on dust particles and their dependence 
on column-averaged $T$ and initial [dust], with lines to represent a least squares fit:

$$
J=9.2 \times 10^{-7}[\text { dust }] e^{0.46(273.16-T)-0.00008(273.16-T)^{3}},
$$

where $J$ is in units of $\mathrm{L}^{-1} \mathrm{~s}^{-1} . J$ values appropriate for mixed-phase clouds may be calculated using Eq. (7) for $T$ and [dust] points below the long dashed line in Fig. 2, which is given by

$$
J_{\max }=0.082 e^{-0.11(273.16-T)} .
$$

For $T$ and [dust] points above this line, mixed-phase clouds could not be formed, $J$ values should be calculated using Eqs. (1) and (2) for deposition nucleation or using Eq. (9) for condensation and immersion nucleation $(\mathrm{RHw} \leq 100 \%)$ :

$$
J_{\text {imm }}=6.2 \times 10^{-7}[\text { dust }] e^{0.44(273.16-T)-0.522(100-\mathrm{RHw})} .
$$

The values of $J_{\text {imm }}\left(\mathrm{L}^{-1} \mathrm{~s}^{-1}\right), T$, and RHw in Eq. (9) are instantaneous, but the values of $J$ and $T$ in Eq. (7) are time and column averages. For the same $T$ value and $\mathrm{RHw}=100, J$ is larger than $J_{\text {imm }}$ by a factor corresponding to a lowering of temperature by about $1 \mathrm{~K}$.

A purpose of this study is to examine whether Eqs. (5) and (7) may be used in climate models to simulate the effect of dust on mixed-phase stratocumulus clouds. It is noted that in the parcel model the size distribution of dust is fixed to intermediate conditions from dust source to remote regions (Zender et al. 2003). When more accurate dust size distributions are available or desired, the following equation may be used to calculate the instantaneous condensation and immersion nucleation rate in climate models:

$$
J_{\mathrm{imm}}=44.3 e^{0.44(273.16-T)-0.522(100-\mathrm{RHw})} \sum_{n} A_{n},
$$

where $A_{n}$ is total surface area $\left(\mathrm{cm}^{2} \mathrm{~cm}^{-3}\right)$ of dust aerosol in the $n$th size bin.

It is further noted that other formulations for deposition nucleation and immersion freezing have been proposed and used in modeling studies, such as prescribing a probability distribution function for the contact angle (Niedermeier et al. 2014; Wang and Liu 2014; Wang et al. 2014; Savre and Ekman 2015b) or specifying the contact angle as a function of temperature (Welti et al. 2012). These contact angle schemes were found to reproduce the $T$ dependence of freezing and predict the size and time dependence of the freezing process (Ickes et al. 2017). Parcel model results based on these contact angle schemes should be compared to those based on
Eqs. (1)-(4) in a future study, which would also provide a range of alternative parameterizations of $N_{i}$ and $J$ for mixed-phase clouds to be used in atmospheric models.

\section{Impact of the new parameterizations in AM4.0}

The new parameterizations for steady-state $N_{i}$ in mixed-phase clouds presented above (for stratocumulus) and in Fan et al. (2017) (for stratus) have been used to calculate ice crystal concentrations in the GFDL AM4.0 (Zhao et al. 2018a). Dust concentrations are predicted in AM4.0 with emissions calculated based on wind speed at $10 \mathrm{~m}$ above surface. The original AM4.0 uses the Rotstayn-Klein microphysics scheme (Rotstayn et al. 2000; Zhao et al. 2018b). In this scheme, the rate of liquid water loss due to the WBF process is proportional to $N_{i}^{2 / 3}$ and the loss integrated over a model time step (1800 s) is not allowed to exceed available water. Gridscale temperature and dust concentration are used to calculate $N_{i}$ based on the new parameterizations [Eq. (5) above and Eqs. (3) and (4) in Fan et al. 2017]. Presently a constant vertical velocity of $0.1 \mathrm{~m} \mathrm{~s}^{-1}$ is specified for calculation of $N_{i}$ in stratus as associated with a warm front. A probability density function of $w$ could be used in future implementations. In the standard AM4.0 the number concentration of ice crystals is calculated based on Meyers et al. (1992), which relates the concentration of INP to ice supersaturation at water saturation and does not depend on dust concentration. We ran AM4.0 for a 6-yr period (1999-2004) with prescribed sea surface temperatures and sea ice cover (Taylor et al. 2000) and with horizontal winds nudged to the National Center for Atmospheric Research-National Centers for Environmental Prediction (NCAR-NCEP) reanalysis (Kalnay et al. 1996). The advantage of using the nudged model is that the effect of two parameterizations can be isolated in the new and original AM4, as the nudging draws the model state close to the reanalysis.

Figure 3 shows the latitude-altitude distribution of in-cloud ice crystal concentration predicted in AM4 with the dust and temperature-dependent parameterization for ice nucleation in mixed-phase clouds, where model $N_{i}$ is averaged zonally and for the period 2000-04 and does not include ice originating from homogeneous nucleation. The contour lines are shown for concentrations from 0.1 to $10 \mathrm{~L}^{-1}$ (Fig. 3). The highest $N_{i}$ contours are found in the middle troposphere over high latitudes and in the tropical upper troposphere. This distribution indicates the dominant role of $T$ in ice nucleation. The decrease of $N_{i}$ with altitude in the upper troposphere is controlled by dust concentration 


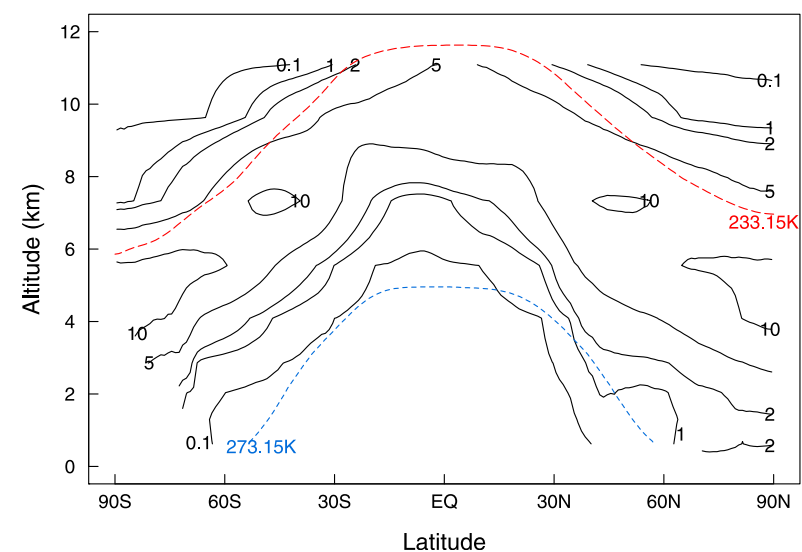

FIG. 3. Annual- and zonal-mean in-cloud ice number concentrations (contour lines; $\mathrm{L}^{-1}$ ) originating from immersion-mode ice nucleation at temperatures above $-40^{\circ} \mathrm{C}$, as predicted by the new dust and temperature-dependent parameterization. Blue and red dashed lines show the mean altitudes for temperatures of $0^{\circ}$ and $-40^{\circ} \mathrm{C}$, respectively.

and by occurrence of cirrus clouds unrelated to immersion freezing on mineral dust particles. By contrast, the Meyers et al. (1992) parameterization predicts $N_{i}$ on the order of $10 \mathrm{~L}^{-1}$ in the high-latitude lower troposphere and continued increase of $N_{i}$ with altitude to values over $100 \mathrm{~L}^{-1}$ (Fig. 4). The model results shown in Fig. 3 are comparable to observed ice crystal concentrations in the Arctic, Antarctica and middle latitudes (e.g., Kikuchi and Hogan 1979; Cooper 1986; Pinto et al. 2001; Rangno and Hobbs 2001; McFarquhar et al. 2007; Avramov et al. 2011; Lloyd et al. 2015; Eidhammer et al. 2010; Mioche et al. 2017; Wolf et al. 2018). In particular, the observations are in better agreement with the annual mean $N_{i}$ predicted with the new parameterization than with the original Meyers et al. (1992) parameterization (Fig. 4).

Figure 5 shows the differences between model results (new - original) averaged over 5 years from 2000 to 2004. The cloud ice water path (IWP) is increased over the Arctic and Antarctica, but is decreased in other regions (Fig. 5a). The largest decreases are found in the extratropical storm tracks. The decreases in IWP reflect smaller $N_{i}$ values than predicted by the original parameterization and a slower WBF process, while the increases in IWP reflect enhanced transport of liquid water to the poles, which subsequently freezes. The polar troposphere is frequently cold enough $\left(T<-40^{\circ} \mathrm{C}\right.$; see Fig. 3) for homogeneous ice nucleation, which does not require a nucleus such as a mineral dust particle. The LWP is increased at all latitudes with a pronounced peak near $60^{\circ} \mathrm{S}$ (Fig. 5b), due to a slower WBF process that transfers water molecules from supercooled liquid drops to ice particles.

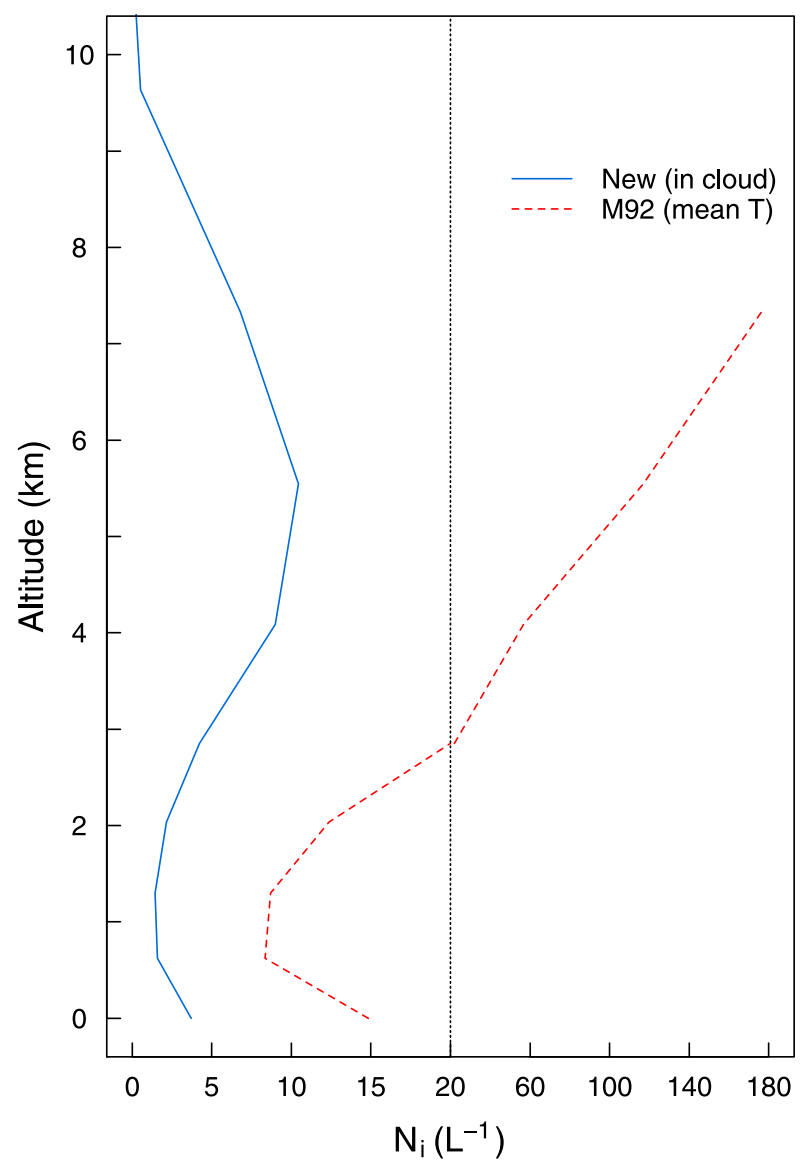

FIG. 4. The vertical distribution of ice crystal concentrations $N_{i}$ averaged annually over the region from $70^{\circ}$ to $85^{\circ} \mathrm{N}$. The solid line ("New" in the legend) shows in-cloud (all clouds) $N_{i}$ originating from immersion freezing on mineral dust particles. The dashed line ("M92" in the legend) shows the concentrations of ice nucleating particles (INP) calculated based on mean temperatures $T$ : INP = $\exp \left[0.1296 \times\left(\mathrm{RH}_{i}-100\right)-0.639\right]$, where $\mathrm{RH}_{i}(\%)$ is the relative humidity over ice at $T$ and water saturation (Meyers et al. 1992). M92 data for $T<-40^{\circ} \mathrm{C}$ are not shown. The dotted line marks a change of scale in the horizontal axis.

An increase of supercooled liquid clouds results in more shortwave (SW) radiation reflected at top of the atmosphere (SWup; Fig. 5c), which is partly compensated by a reduction in the outgoing longwave radiation (OLR; Fig. 5d). The global 5-yr average absorbed SW (SWabs) decreases from 242.1 to $236.6 \mathrm{~W} \mathrm{~m}^{-2}$ and OLR decreases from 238.0 to $235.9 \mathrm{~W} \mathrm{~m}^{-2}$, respectively. These changes in SWabs and OLR with magnitudes of several watts per square meter are significant relative to Earth's energy imbalance, which is on the average $0.68 \mathrm{~W} \mathrm{~m}^{-2}$ net absorption in recent years (von Schuckmann et al. 2016; Dieng et al. 2017). The global 5-yr averages and changes for other diagnostics are shown in the appendix (Table A1). Pronounced changes are shown for LWP and midlevel cloud amount 
(a)

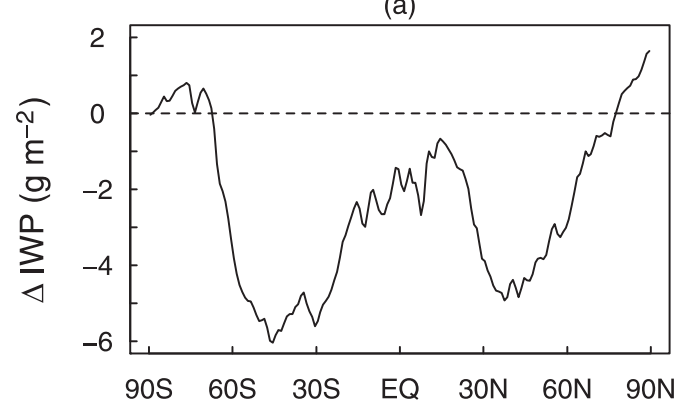

(c)

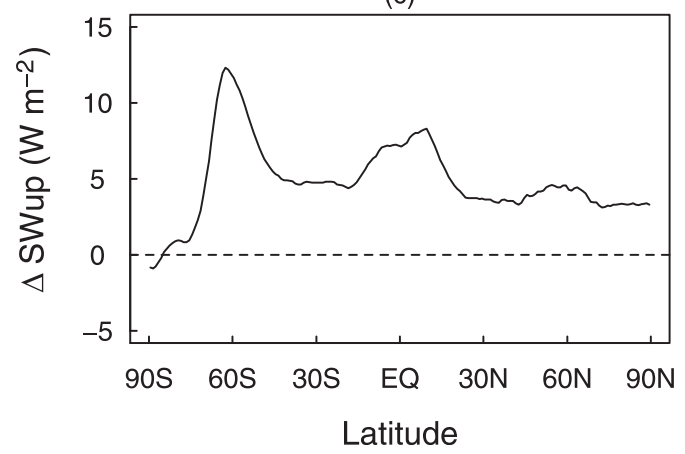

(b)

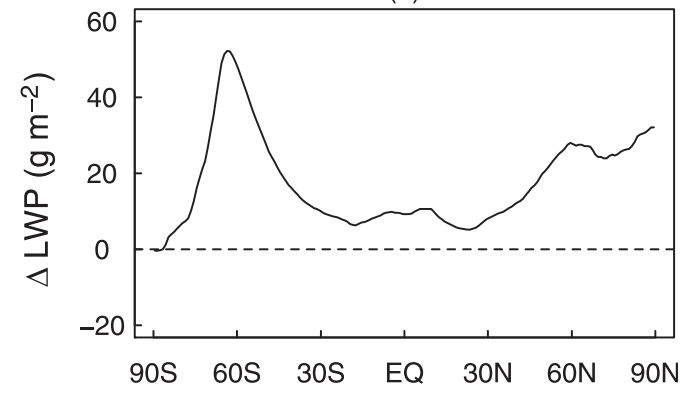

(d)

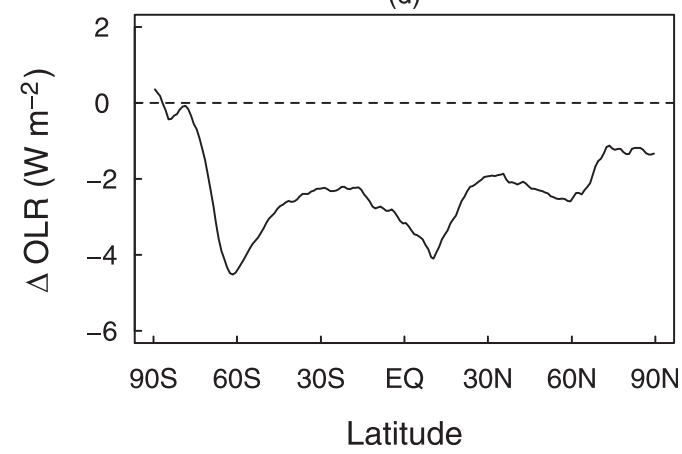

FIG. 5. The zonal-mean differences ( $\Delta$ indicates new minus original) in (a) ice water path (IWP), (b) liquid water path (LWP), (c) reflected shortwave (SWup) at the top of the atmosphere, and (d) outgoing longwave radiation (OLR), based on nudged AM4.0 simulations from 2000 to 2004 using the new and the original parameterizations for ice crystal number concentrations.

as more supercooled liquid cloud is sustained in the new model. Consequently, large changes are also estimated for net radiation at the top of the atmosphere (TOA) and for cloud radiative effects (Table A1).

The new parameterization may be evaluated with multiple metrics of model performance using aircraft, ground-based, and satellite observations including cloud cover, IWP, LWP, radiative effects, and phase partitioning. Here we focus on ice-liquid partitioning, while model-observation comparisons for cloud cover, IWP and LWP will be reported in the future. Multiple studies have reported and analyzed global, regional and seasonal distributions of ice fraction or liquid fraction in clouds based on satellite measurements at fine footprints that were averaged to larger grid boxes (Choi et al. 2010; Hu et al. 2010; Cesana and Chepfer 2013; Tan et al. 2014; Cesana et al. 2015; Hirakata et al. 2014; Huang et al. 2015). These data are "presence" or "occurrence frequency" phase ratios (FPR) based on satellite remote sensing. A comparison of the satellite data with in situ aircraft observations shows 1) CloudAerosol Lidar and Infrared Pathfinder Satellite $\mathrm{Ob}$ servations (CALIPSO) data lead to somewhat a better representation of the cloud phase than passive sensor retrievals and 2) they were in good agreement with in situ observations where both the lidar and the in situ sensor were not limited due to either laser attenuation for the lidar or precipitation contamination for the in situ sensor (most likely at $T<-10^{\circ} \mathrm{C}$ ) (Cesana et al. 2016). We choose to compare model results with data from the Global Climate Model-Oriented CALIPSO Cloud Product (GOCCP) (Chepfer et al. 2010). This dataset of ice fraction (FPR) is weighted toward cloud-top conditions because the lidar does not penetrate deep into optically thick clouds (Cesana et al. 2015). We follow Komurcu et al. (2014) to compare mass phase ratio $($ MPR $=$ ice/(ice + liquid), water mass mixing ratios) from models with the FPR data from CALIPSO-GOCCP. We also compare modeled FPR estimated using a CALIPSO simulator with the observations as in Cesana et al. (2015).

Figure 6 shows a comparison of ice fraction between AM4.0 model results and the CALIPSO-GOCCP data. The global-scale nighttime grid-average observations (FPR) from 2007 to 2011 are averaged over temperature bins of $3^{\circ}$ (solid line in Fig. 6; "OBS" in the legend) (Cesana and Chepfer 2013). One year of daily instantaneous three-dimensional global fields of ice water fraction (MPR) are similarly averaged for the model results, and are shown by the dashed and dotted 


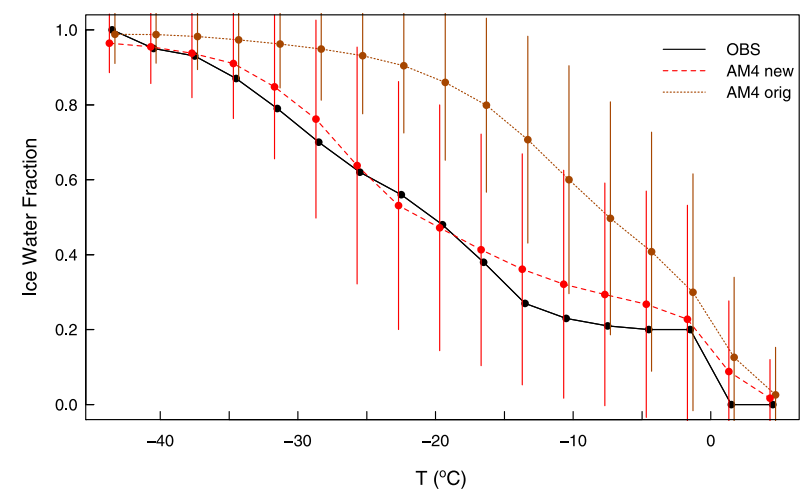

FIG. 6. The relationships between ice fraction and temperature. Solid line ("OBS" in the legend) shows the occurrence frequency phase ratio (FPR) observed by CALIPSO-GOCCP. Dashed and dotted lines show the mass phase ratio (MPR) simulated in AM4.0 with the new parameterization of ice crystal concentration ("new") and with Meyers et al. (1992) parameterization of ice nucleating particle (as a proxy of ice crystals) concentration ("orig"), respectively. The global-scale observations from 2007 to 2011 are averaged by temperature bins of $3^{\circ} \mathrm{C}$ (Cesana and Chepfer 2013). One year of daily instantaneous three-dimensional global fields of ice fraction are similarly averaged for the model results. The median $T$ is shifted by $\pm 0.2^{\circ} \mathrm{C}$ for the model results to better show the standard deviations (vertical lines).

lines for the "new" and "original" parameterizations in AM4.0 ("new" and "orig" in the legend), respectively. The "new" results compare well with the observations, and both of them show lower ice fractions than the "original" results, most significantly from $-30^{\circ}$ to $-10^{\circ} \mathrm{C}$ (Fig. 6). This comparison suggests that one possible reason that climate models underestimate liquid water path may be related to the ice nucleation rate and ice crystal number concentration and associated WBF process (e.g., Lawson and Gettelman 2014; VergaraTemprado et al. 2018). Further comparisons of ice fractions are presented in the appendix (Fig. A8).

It is noted that the good agreement between CALIPSOGOCCP and the new AM4 shown in Fig. 6 could be fortuitous. Indeed, a better agreement is obtained between the observations and original AM4 when a lidar simulator is used to screen model output (Fig. 7a). Ice fractions obtained for new AM4 with the simulator are lower than the observations (Fig. 7a). Presently AM4 does not explicitly consider ice clouds originating from heterogeneous ice nucleation at RH below water saturation (i.e., deposition nucleation on dry dust particles or immersion freezing on dust particles with an aqueous shell) in the mixed-phase temperature regime. Inclusion of these ice clouds in the model would increase the average ice fraction, thus compensating for the low bias shown in Fig. 7a. It is also likely that the lidar simulator has underestimated the back scattering by ice particles and thus FPR in the model. Liquid is
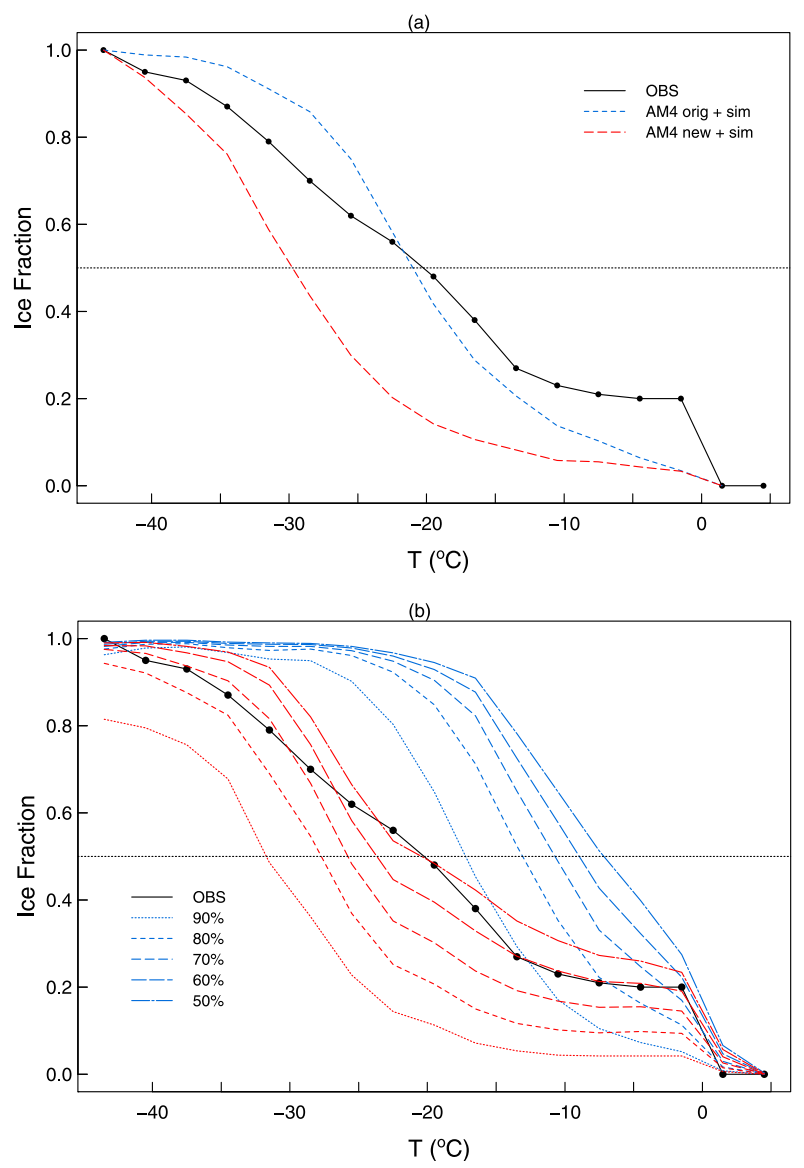

FIG. 7. The relationships between ice fraction (FPR) and temperature. (a) CALIPSO-GOCCP observations (OBS; solid line) are compared to the original AM4 with the GOCCP lidar simulator (dashed lines) and the new AM4 with the simulator (long-dashed line). (b) The observations (solid line) are compared to the original AM4 (blue lines) and the new AM4 (red lines) with different thresholds for the identification of ice clouds (see the legend for details; e.g., if ice mass fraction $>90 \%$, then there is an ice cloud; otherwise there is a liquid cloud; no lidar simulator).

often present in ice-containing grid boxes, which largely affects the simulated perpendicular attenuated backscatter signal and results in grid boxes dominated by liquid cloud occurrences even when the ice water content is larger than the liquid water content (Cesana et al. 2015).The simulator makes assumptions about the number, size, shape and orientation for ice particles (Cesana and Chepfer 2013), whose variations in space and time are not readily accounted for.

Alternatively, we identify ice clouds in AM4 using a threshold of ice mass fraction. If ice mass fraction in a grid box is above this threshold the clouds are identified as ice, otherwise as liquid. We estimate the mean FPR for temperature bins over all model grids with a total condensate greater than $4 \times 10^{-6} \mathrm{~kg} \mathrm{~kg}^{-1}$ for five different thresholds $(50 \%, 60 \%, 70 \%, 80 \%$ and $90 \%)$. 


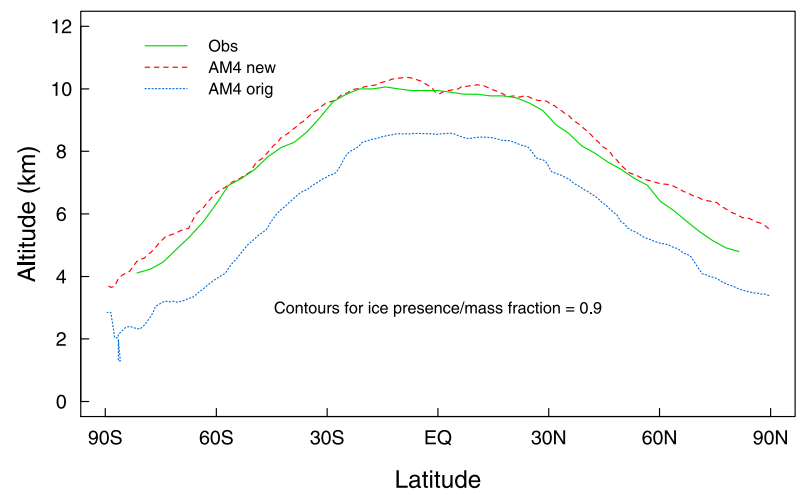

FIG. 8. Contour lines drawn for an ice fraction of 0.9 in the latitude-altitude space, based on annually and zonally averaged phase ratios (solid: observation; dashed: new AM4.0; dotted: original AM4.0). The CALIPSO-GOCCP data is read from Cesana et al. (2015).

The results are compared to the CALIPSO-GOCCP observations in Fig. 7b. The original AM4 results (blue lines) show rapid increase of ice fraction between $0^{\circ}$ and $-20^{\circ} \mathrm{C}$ and are larger than the observations (black line). The new AM4 results (red lines) are generally in better agreement with the observations, especially for a $60 \%$ threshold and $T$ between $0^{\circ}$ and $-15^{\circ} \mathrm{C}$ and for a $70 \%$ threshold and $T$ below $-30^{\circ} \mathrm{C}$.

Cesana et al. (2015) applied the CALIPSO-GOCCP retrieval algorithm to model simulated cloud ice and liquid water contents and found the temperature difference between mean FPR (simulated retrieval) and MPR (straight model output) is about $2 \mathrm{~K}$ when they are both equal to 0.9 , increasing as the ratios decrease. Figure 8 shows the altitudes where observed and model phase ratios (annual and zonal averages) are equal to 0.9 as a function of latitude. Smaller ratios are found below and larger ratios above the lines. The contour line predicted by the "original" AM4.0 is lower than the observation ("Obs" in the legend) by about $2 \mathrm{~km}$, while the "new" AM4.0 is in good agreement with the observation except at high latitudes in the Northern Hemisphere (Fig. 8). It is noted that the modeled ratios are also dependent on the terminal velocity of ice particles, which varies with particle size and habit. The comparison shown in Fig. 8 is thus subject to any uncertainty in the calculation of ice sedimentation. Processes subsequent to ice nucleation are at least as important in determining phase (Komurcu et al. 2014).

\section{Summary}

In summary, we presented a new parameterization for ice nucleation rate and number concentration based on parcel model simulations with idealized conditions

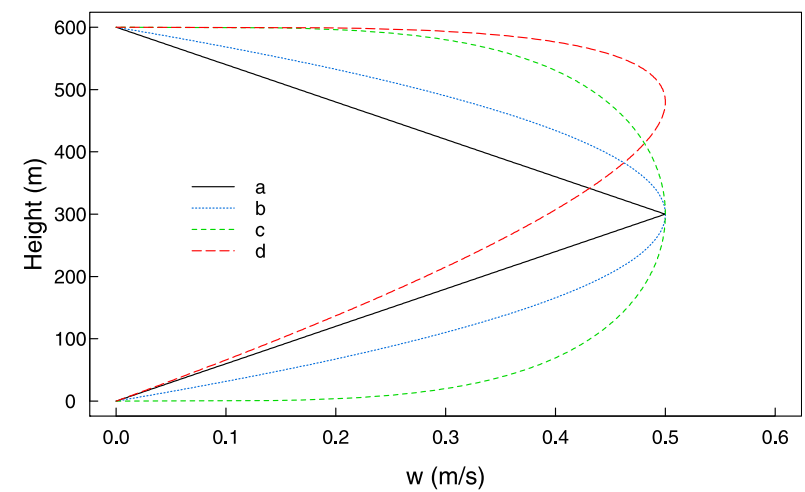

FIG. A1. Different vertical profiles of $w$ prescribed for the updraft in a stratocumulus cloud. The sign is inverted for the downdrafts. Lines "a" and "b" are two approximations of the average updraft shown in Solomon et al. (2011), while line "c" resembles that shown in Yang et al. (2013) and line "d" resembles that shown in Roesler et al. (2017). Note that absolute values less than $0.04 \mathrm{~m} \mathrm{~s}^{-1}$ are skipped to keep the parcel moving up and down in a cellular convection.

for stratus and stratocumulus. This parcel model approach is admittedly not a reliable representation of real clouds at all times. The discrepancies may arise from different turbulence regimes, such as entrainment (neglected in the parcel model), INPs other than mineral dust (not considered in the parcel model simulations), or different dust concentrations, mineralogical compositions and size distributions. A mineral dust and temperature-dependent parameterization for ice nucleation in the mixed-phase region might be expected to yield a more accurate accounting of ice nucleating particles and ice crystal concentrations and would therefore lead to improved cloud ice-liquid partitioning, and consequently more accurate calculation

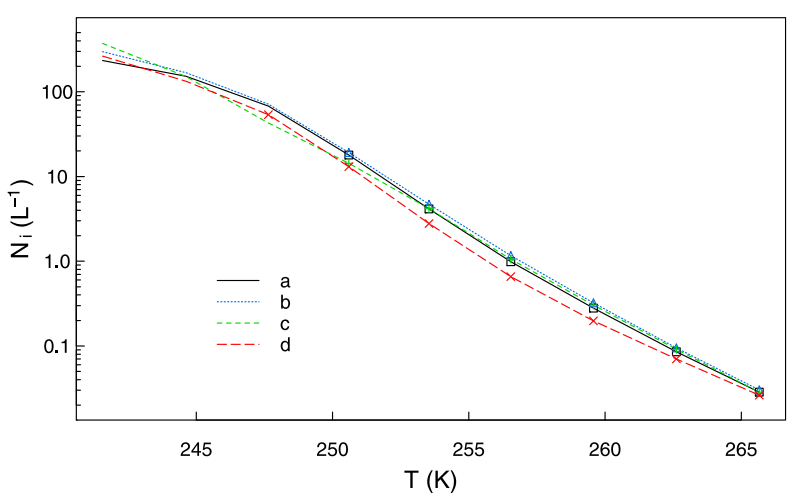

FIG. A2. Number concentration of ice crystals (time-weighted column-average $N_{i}$ for $D<200 \mu \mathrm{m}$ ) in stratocumulus clouds as a function of temperature (column-average $T$ ). The lines (see legend) connect simulation results with different vertical velocity profiles (see Fig. A1). The symbols indicate the results with both ice and liquid hydrometeors. 


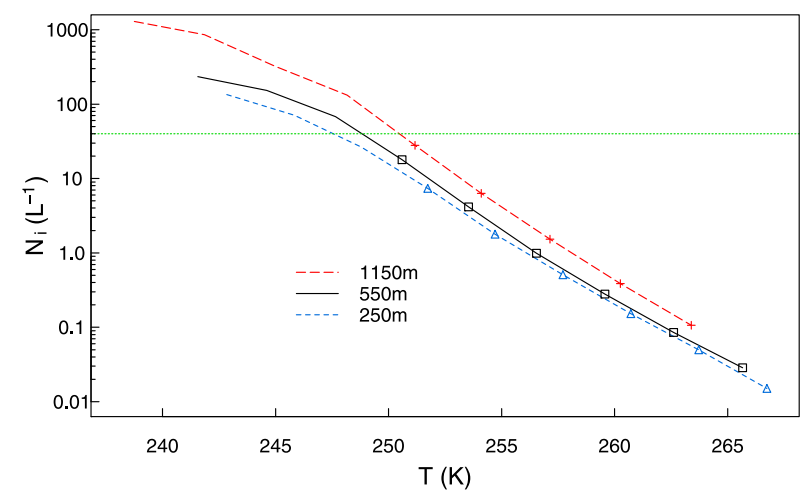

FIG. A3. As in Fig. A2, but for different cloud thicknesses.

of radiative fluxes, in future climate and weather models. It is also useful for studying the role of dust emissions in paleoclimate through cloud modification, in addition to aerosol direct radiative effect and iron fertilization of ocean primary productivity, which increases oceanic uptake of carbon dioxide and emission of dimethylsulfide (Bender 2013).

The new parameterization for ice nucleation in mixed-phase clouds presented in this paper and in Fan et al. (2017), as implemented in the GFDL atmospheric model, version 4.0 (AM4.0), predicts thermodynamic phase in good agreement with the CALIPSO-GOCCP data when the model results for mass phase ratio (MPR) and observations for frequency phase ratio (FPR) are both averaged globally by temperature bins. However, the model FPR results based on a CALIPSO simulator are lower than the observations. Additionally, large changes in model results are found from the original to the new AM4.0 in cloud cover (not shown), ice and liquid water paths, and reflected shortwave and outgoing longwave radiation at the top of the atmosphere. Further work is required in concert with other model development activities, including the implementation of ice nucleation in different cloud microphysics schemes, assessment of sensitivity to parameters uncertainties, and assessment of potential impacts of minor ice nucleating particles and secondary ice particle productions (Kanji et al. 2017). Continued model evaluation in the mixed-phase region is essential for improvement of cloud-phase simulation. This may be accomplished by comparisons of model results with in situ and remote sensing measurements of cloud ice and liquid water fractions and global and seasonal observations of cloud cover, and ice and liquid water paths.

Acknowledgments. We thank G. Cesana and H. Chepfer for the CALIPSO-GOCCP data and the lidar simulator.

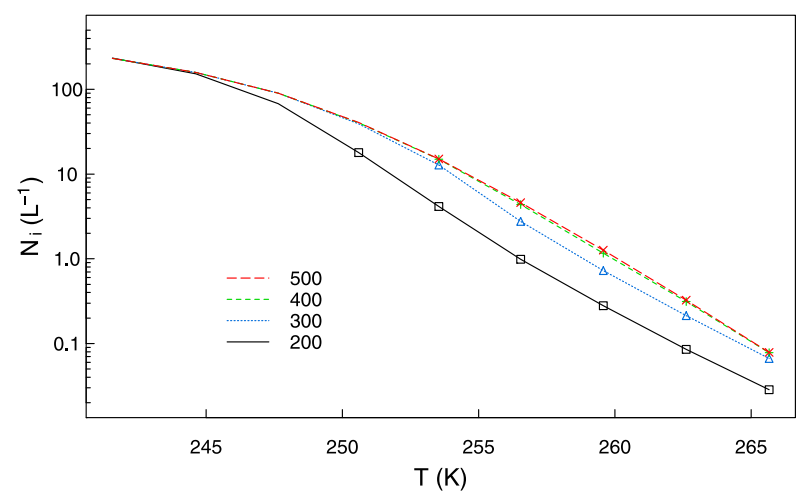

FIG. A4. Number concentration of ice crystals (time-weighted column-average $N_{i}$ ) in stratocumulus clouds as a function of average temperature. The lines (see the legend) connect simulation results for different critical sizes (200-500- $\mu$ m diameters) used to divide ice and snow particles.

Three anonymous reviewers provided many useful comments and suggestions. Richard Hemler helped with implementing the new parameterization for ice nucleation in AM4.

\section{APPENDIX}

\section{Sensitivity Simulations}

Stratocumulus clouds may have different thicknesses $(H)$ and vertical velocity $(w)$ profiles. In the following, we compare model results of $N_{i}$ for four profiles of $w$ (Fig. A1), three maximum values of $w\left(0.5,1.0,1.5 \mathrm{~m} \mathrm{~s}^{-1}\right.$,

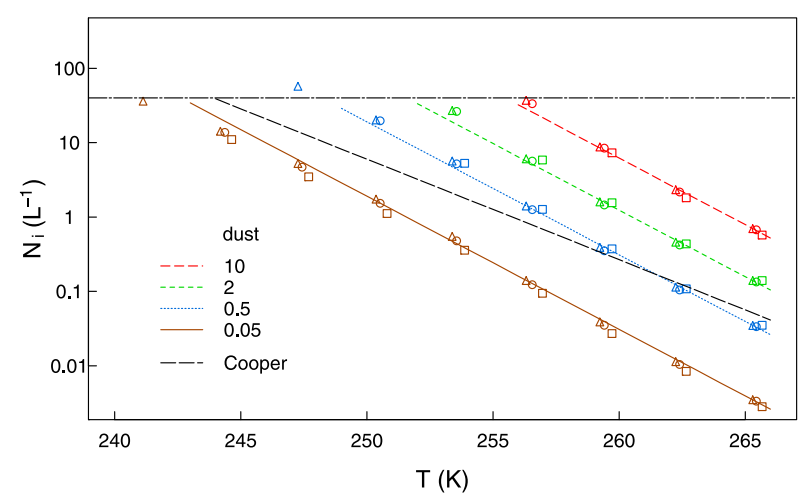

FIG. A5. Number concentration of ice crystals (time-weighted column-average $N_{i}$ for $D<200 \mu \mathrm{m}$ ) in stratocumulus clouds as a function of average temperature. The lines (see the legend) indicate calculations using Eq. (5) for [dust] $=10,2,0.5$, and $0.05 \mu \mathrm{g} \mathrm{m}^{-3}$ and using Eq. (6) based on Cooper (1986). The symbols indicate parcel model results for different maximum vertical velocities (see profile "a" in Fig. A1): a square for $0.5 \mathrm{~m} \mathrm{~s}^{-1}$, a circle for $1.0 \mathrm{~m} \mathrm{~s}^{-1}$, and a triangle for $1.5 \mathrm{~m} \mathrm{~s}^{-1}$. The horizontal line $\left(N_{i}=\right.$ $40 \mathrm{~L}^{-1}$ ) is drawn for reference (approximately the maximum $N_{i}$ for ice-liquid coexistence). 


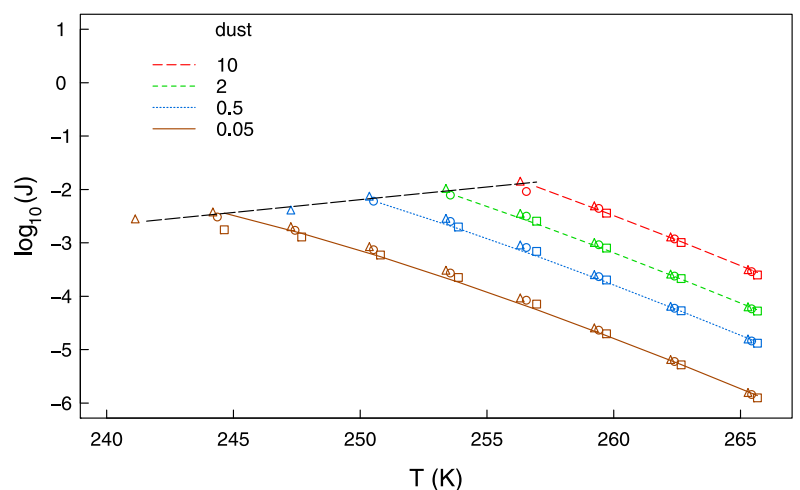

FIG. A6. Common log of the rate of ice nucleation (timeweighted column-average $J ; \mathrm{L}^{-1} \mathrm{~s}^{-1}$ ) as a function of average temperature. The symbols indicate results from individual parcel model simulations for different maximum vertical velocities (see profile "a" in Fig. A1): a square for $0.5 \mathrm{~m} \mathrm{~s}^{-1}$, a circle for $1.0 \mathrm{~m} \mathrm{~s}^{-1}$, and a triangle for $1.5 \mathrm{~m} \mathrm{~s}^{-1}$. The lines indicate calculations using Eq. (7) for [dust] $=10,2,0.5$, and $0.05 \mu \mathrm{g} \mathrm{m}^{-3}$ and using Eq. (8) for the upper limit (long-dashed black line) below which mixed-phase stratocumulus clouds may be sustained.

with profile "a" in Fig. A1), three specifications of $H$ $(250,550,1150 \mathrm{~m})$, and four critical sizes $(D=200,300$, $400,500 \mu \mathrm{m})$ for ice-snow partitioning. We find that the model results are close to that calculated using Eq. (5) or Eq. (7) (Figs. A2-A6 ). Variations of $N_{i}$ with $H$ may be accounted for by offsetting $T$ in Eq. (5), for instance, lowering $T$ from the column mean by $\sim 1.5 \mathrm{~K}$ for $H=$ $1150 \mathrm{~m}$, or increasing $T$ by $\sim 0.5 \mathrm{~K}$ for $H=250 \mathrm{~m}$ (Fig. A3). Similarly, the differences in $N_{i}$ between profiles "a" and "d" (Fig. A2) may be accounted for by increasing $T$ from the column mean by $\sim 1 \mathrm{~K}$ for profile "d," which is characterized by more rapid up and down motions near the cloud top than near the bottom (Fig. A1). By contrast, the other profiles are symmetrical about the midheight.

Figure A7 shows the dependence of $N_{i}$ on initial/base pressure $P$ : the ratio of $N_{i}$ at $P$ to $N_{i}$ at $950 \mathrm{hPa}$ has approximately a $1: 1$ relationship with the ratio of $P / 950$ at a temperature of $262 \mathrm{~K}$ (for [dust] $=2.0 \mu \mathrm{g} \mathrm{m}^{-3}$ ). The slope is slightly smaller at a higher temperature and larger at a lower temperature. The values of $N_{i}$ calculated using Eq. (5), which is derived based on simulations with an initial/base pressure of $950 \mathrm{hPa}$, should be scaled by the ratio of $P / 950$ for different pressures.

Figure A 8 shows the relationships between the ice water fraction (mass phase ratio or MPR) and temperature $T$ for five latitude bands $\left(90^{\circ}-70^{\circ} \mathrm{S}, 70^{\circ}-40^{\circ} \mathrm{S}\right.$, $\left.40^{\circ} \mathrm{S}-40^{\circ} \mathrm{N}, 40^{\circ}-70^{\circ} \mathrm{N}, 70^{\circ}-90^{\circ} \mathrm{N}\right)$. When the Meyers et al. (1992) parameterization is used, there are small variations among the latitude bands in the relationship between MPR and $T$ (top panel). There are more variations among the latitude bands when the new

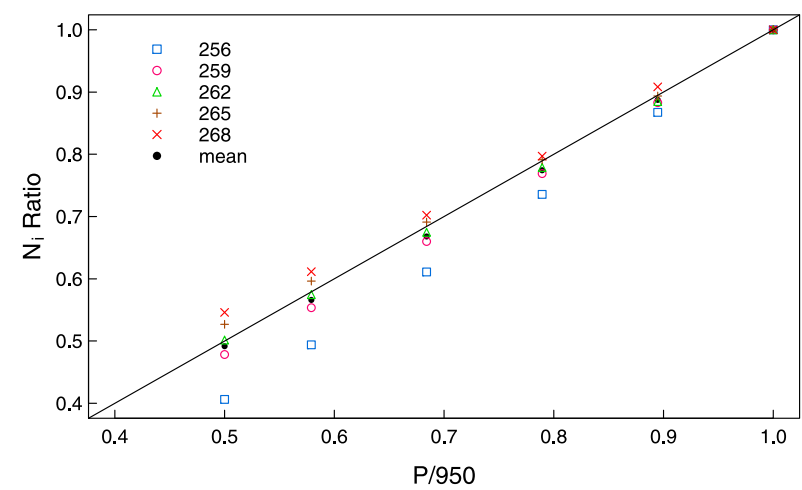

FIG. A7. The ratio of average $N_{i}$ at pressure $P$ to that at $950 \mathrm{hPa}$ vs $P / 950$. The solid line indicates a 1:1 relationship. The symbols indicate simulation results at various temperatures and their mean (see the legend).

parameterization is used (bottom panel). In particular, larger ice water fractions are simulated in the $40^{\circ} \mathrm{S}-40^{\circ} \mathrm{N}$ and $40^{\circ}-70^{\circ} \mathrm{N}$ bands than in the other bands from $-30^{\circ}$ to $-10^{\circ} \mathrm{C}$, because simulated concentrations
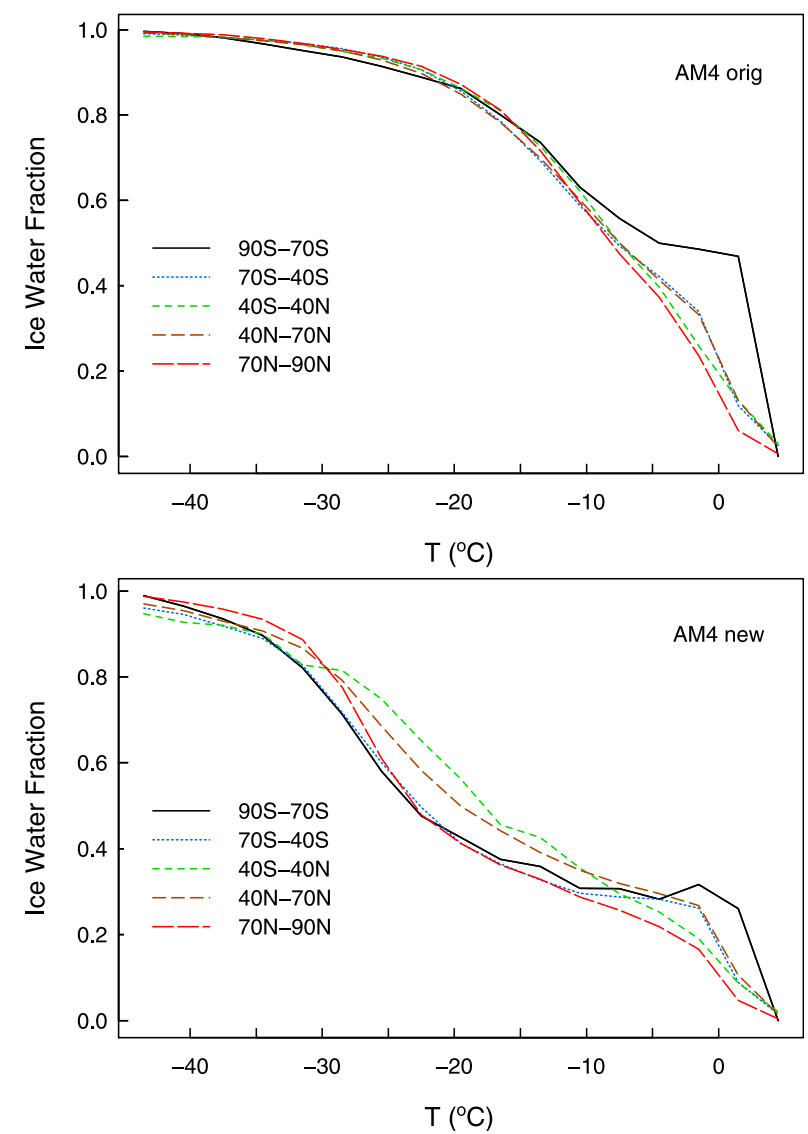

FIG. A8. The relationships between ice water fraction and temperature for five latitude bands (see the legend), based on AM4.0 simulations using (top) the Meyers et al. (1992) parameterization and (bottom) the new parameterization. 
TABLE A1. Global 5-yr averages for selected AM4 results.

\begin{tabular}{|c|c|c|c|c|}
\hline Variable & Original AM4 & New AM4 & New minus original & Description \\
\hline $\operatorname{LWP}\left(\mathrm{g} \mathrm{m}^{-2}\right)$ & 42.55 & 57.17 & 14.62 & Liquid water path \\
\hline IWP $\left(\mathrm{g} \mathrm{m}^{-2}\right)$ & 47.74 & 43.91 & -3.83 & Ice water path \\
\hline CLD high (\%) & 38.18 & 39.00 & 0.82 & High cloud cover \\
\hline CLD mid (\%) & 18.68 & 20.54 & 1.86 & Middle cloud cover \\
\hline CLD low (\%) & 36.56 & 36.47 & -0.09 & Low cloud cover \\
\hline LW CRE $\left(\mathrm{W} \mathrm{m}^{-2}\right)$ & 20.71 & 22.46 & 1.75 & Longwave cloud radiative effect \\
\hline SW CRE $\left(\mathrm{W} \mathrm{m}^{-2}\right)$ & -54.17 & -60.18 & -6.01 & Shortwave cloud radiative effect \\
\hline SWnet,toa $\left(\mathrm{W} \mathrm{m}^{-2}\right)$ & 242.08 & 236.59 & -5.49 & Net SW at TOA \\
\hline SWnet,surf ( $\left.\mathrm{W} \mathrm{m}^{-2}\right)$ & 166.01 & 161.36 & -4.66 & Shortwave absorbed by surface \\
\hline $\operatorname{OLR}\left(\mathrm{W} \mathrm{m}^{-2}\right)$ & 238.03 & 235.94 & -2.09 & Outgoing longwave radiation \\
\hline LWnet,surf $\left(\mathrm{W} \mathrm{m}^{-2}\right)$ & 59.60 & 58.40 & -1.21 & Net longwave emitted by surface \\
\hline Rnet,toa $\left(\mathrm{W} \mathrm{m}^{-2}\right)$ & $4.05^{\mathrm{a}}$ & 0.65 & -3.40 & Net radiation at TOA \\
\hline Precip $\left(\mathrm{mm} \mathrm{day}{ }^{-1}\right)$ & 2.87 & 2.87 & 0.00 & Precipitation \\
\hline
\end{tabular}

${ }^{a}$ A threshold mean droplet radius for the initiation of rain is specified to be $7.0 \mu \mathrm{m}$ in both the original and new AM4.0 simulations as in AM3 (Golaz et al. 2013), which was specified to be $8.5 \mu \mathrm{m}$ in Zhao et al. (2018a). This is causing a large Rnet in the "original" simulation.

of mineral dust are higher in the former bands than in the latter bands (not shown). This result is generally similar to the CALIPSO-GOCCP observations (Cesana and Chepfer 2013). Table A1 compares global average cloud and radiation properties in the new and original AM4.0 simulations. High, middle, and low cloud cover are calculated assuming overlaps decaying exponentially with distance between cloud layers for cloud top pressures $<440,440-680$, and $>680 \mathrm{hPa}$, respectively (Zhao et al. 2018b). Cloud radiative effects are calculated as the differences between all-sky and clear-sky averages.

\section{REFERENCES}

Alpert, P. A., and D. A. Knopf, 2016: Analysis of isothermal and cooling-rate-dependent immersion freezing by a unifying stochastic ice nucleation model. Atmos. Chem. Phys., 16, 2083-2107, https://doi.org/10.5194/acp-16-2083-2016.

Avramov, A., and Coauthors, 2011: Toward ice formation closure in Arctic mixed-phase boundary layer clouds during ISDAC. J. Geophys. Res., 116, D00T08, https://doi.org/ 10.1029/2011JD015910.

Bender, M., 2013: Climate-biosphere interactions on glacialinterglacial timescales. Global Biogeochem. Cycles, 17, 1082, https://doi.org/10.1029/2002GB001932.

Bodas-Salcedo, A., P. G. Hill, K. D. Williams, P. R. Field, J. C. Manners, and P. Hyder, 2016: Large contribution of supercooled liquid clouds to the solar radiation budget of the Southern Ocean. J. Climate, 29, 4213-4228, https://doi.org/ 10.1175/JCLI-D-15-0564.1.

Cesana, G., and H. Chepfer, 2013: Evaluation of the cloud thermodynamic phase in a climate model using CALIPSO-GOCCP. J. Geophys. Res. Atmos., 118, 7922-7937, https://doi.org/ 10.1002/jgrd.50376.

- D. E. Waliser, X. Jiang, and J.-L. F. Li, 2015: Multimodel evaluation of cloud phase transition using satellite and reanalysis data.J. Geophys. Res. Atmos., 120, 7871-7892, https:// doi.org/10.1002/2014JD022932.
__ , and Coauthors, 2016: Using in situ airborne measurements to evaluate three cloud phase products derived from CALIPSO. J. Geophys. Res. Atmos., 121, 5788-5808, https:// doi.org/10.1002/2015JD024334.

Chepfer, H., S. Bony, D. Winker, G. Cesana, J. L. Dufresne, P. Minnis, C. J. Stubenrauch, and S. Zeng, 2010: The GCMOriented CALIPSO Cloud Product (CALIPSO-GOCCP). J. Geophys. Res., 115, D00H16, https://doi.org/10.1029/ 2009JD012251.

Choi, Y.-S., C.-H. Ho, S.-W. Kim, and R. S. Lindzen, 2010: Observational diagnosis of cloud phase in the winter Antarctic atmosphere for parameterizations in climate models. Adv. Atmos. Sci., 27, 1233-1245, https://doi.org/10.1007/s00376-010-9175-3.

Cooper, W. A., 1986: Ice initiation in natural clouds. Precipitation Enhancement-A Scientific Challenge, Meteor. Monogr., No. 43, Amer. Meteor. Soc., 29-32.

de Boer, G., T. Hashino, and G. J. Tripoli, 2010: Ice nucleation through immersion freezing in mixed-phase stratiform clouds: Theory and numerical simulations. Atmos. Res., 96, 315-324, https://doi.org/10.1016/j.atmosres.2009.09.012.

Dieng, H. B., A. Cazenave, B. Meyssignac, K. von Schuckmann, and H. Palanisamy, 2017: Sea and land surface temperatures, ocean heat content, Earth's energy imbalance and net radiative forcing over the recent years. Int. J. Climatol., 37, 218-229, https://doi.org/10.1002/joc.4996.

Eidhammer, T., and Coauthors, 2010: Ice initiation by aerosol particles: Measured and predicted ice nuclei concentrations versus measured ice crystal concentrations in an orographic wave cloud. J. Atmos. Sci., 67, 2417-2436, https://doi.org/ 10.1175/2010JAS3266.1.

Fan, J., S. J. Ghan, M. Ovchinnikov, X. Liu, P. R. Rasch, and A. Korolev, 2011: Representation of Arctic mixed-phase clouds and Wegener-Bergeron-Findeisen process in climate models-Perspectives from a cloud-resolving study. J. Geophys. Res., 116, D00T07, https://doi.org/10.1029/ 2010JD015375.

Fan, S.-M., D. A. Knopf, A. J. Heymsfield, and L. J. Donner, 2017: Modeling of aircraft measurements of ice crystal concentration in the Arctic and a parameterization for mixed-phase cloud. J. Atmos. Sci., 74, 3799-3814, https://doi.org/10.1175/ JAS-D-17-0037.1. 
Fridlind, A. M., and A. S. Ackerman, 2018: Simulations of Arctic mixed-phase boundary layer clouds: Advances in understanding and outstanding questions. Mixed-Phase Clouds: Observations and Modeling, Elsevier, 153-183, https://doi.org/ 10.1016/B978-0-12-810549-8.00007-6.

— , B. van Diedenhoven, A. S. Ackerman, A. Avramov, A. Mrowiec, H. Morrison, P. Zuidema, and M. D. Shupe, 2012: A FIRE-ACE/SHEBA case study of mixed-phase Arctic boundary layer clouds: Entrainment rate limitations on rapid primary ice nucleation processes. J. Atmos. Sci., 69, 365-389, https://doi.org/10.1175/JAS-D-11-052.1.

Fu, S., and H. Xue, 2017: The effect of ice nuclei efficiency on Arctic mixed-phase clouds from large-eddy simulations. J. Atmos. Sci., 74, 3901-3913, https://doi.org/10.1175/JAS-D-17-0112.1.

Golaz, J.-C., L. W. Horowitz, and H. Levy II, 2013: Cloud tuning in a coupled climate model: Impact on 20th century warming. Geophys. Res. Lett., 40, 2246-2251, https://doi.org/10.1002/ grl.50232.

Hirakata, M., H. Okamoto, Y. Hagihara, T. Hayasaka, and R. Oki, 2014: Comparison of global and seasonal characteristics of cloud phase and horizontal ice plates derived from CALIPSO with MODIS and ECMWF. J. Atmos. Oceanic Technol., 31, 2114-2130, https://doi.org/10.1175/JTECH-D-13-00245.1.

Hu, Y., S. Rodier, K.-M. Xu, W. Sun, J. Huang, B. Lin, P. Zhai, and D. Josset, 2010: Occurrence, liquid water content, and fraction of supercooled water clouds from combined CALIOP/IIR/MODIS measurements. J. Geophys. Res., 115, D00H34, https://doi.org/10.1029/2009JD012384.

Huang, Y., A. Protat, S. T. Siems, and M. J. Manton, 2015: A-Train observations of maritime midlatitude storm-track cloud systems: Comparing the Southern Ocean against the North Atlantic. J. Climate, 28, 1920-1939, https://doi.org/10.1175/ JCLI-D-14-00169.1.

Ickes, L., A. Welti, and U. Lohmann, 2017: Classical nucleation theory of immersion freezing: Sensitivity of contact angle schemes to thermodynamic and kinetic parameters. Atmos. Chem. Phys., 17, 1713-1739, https://doi.org/ 10.5194/acp-17-1713-2017.

Jolly, B., P. Kuma, A. McDonald, and S. Parsons, 2018: An analysis of the cloud environment over the Ross Sea and Ross Ice Shelf using Cloudsat/CALIPSO satellite observations: The importance of synoptic forcing. Atmos. Chem. Phys., 18, 9723-9739, https://doi.org/10.5194/acp-18-9723-2018.

Kalnay, E., and Coauthors, 1996: The NCEP/NCAR 40-Year Reanalysis Project. Bull. Amer. Meteor. Soc., 77, 437-471, https:// doi.org/10.1175/1520-0477(1996)077<0437:TNYRP>2.0.CO;2.

Kanji, Z. A., L. A. Ladino, H. Wex, Y. Boose, M. Burkert-Kohn, D. J. Cziczo, and M. Krämer, 2017: Overview of ice nucleating particles. Ice Formation and Evolution in Clouds and Precipitation: Measurement and Modeling Challenges, Meteor. Monogr., No. 58, Amer. Meteor. Soc., https://doi.org/10.1175/ AMSMONOGRAPHS-D-16-0006.1.

Kikuchi, K., and A. W. Hogan, 1979: Properties of diamond dust type ice crystals observed in summer season at AmundsenScott South Pole Station, Antarctica. J. Meteor. Soc. Japan, 57, 180-190, https://doi.org/10.2151/jmsj1965.57.2_180.

Knopf, D. A., and P. A. Alpert, 2013: A water activity based model of heterogeneous ice nucleation kinetics for freezing of water and aqueous solution droplets. Faraday Discuss., 165, 513-534, https://doi.org/10.1039/c3fd00035d.

Komurcu, M., and Coauthors, 2014: Intercomparison of the cloud water phase among global climate models. J. Geophys. Res. Atmos., 119, 3372-3400, https://doi.org/10.1002/2013JD021119.
Korolev, A., 2007: Limitations of the Wegener-BergeronFindeisen mechanism in the evolution of mixed-phase clouds. J. Atmos. Sci., 64, 3372-3375, https://doi.org/10.1175/ JAS4035.1.

Kulkarni, G., C. Sanders, K. Zhang, X. Liu, and C. Zhao, 2014: Ice nucleation of bare and sulfuric acid-coated mineral dust particles and implication for cloud properties. J. Geophys. Res. Atmos., 119, 9993-10011, https://doi.org/10.1002/ 2014JD021567.

Lawson, R. P., and A. Gettelman, 2014: Impact of Antarctic mixedphase clouds on climate. Proc. Natl. Acad. Sci. USA, 111, 18156-18161, https://doi.org/10.1073/pnas.1418197111.

Lloyd, G., and Coauthors, 2015: Observations and comparisons of cloud microphysical properties in spring and summertime Arctic stratocumulus clouds during the ACCACIA campaign. Atmos. Chem. Phys., 15, 3719-3737, https://doi.org/10.5194/ acp-15-3719-2015.

Mace, G. G., and A. Protat, 2018: Clouds over the Southern Ocean as observed from the $\mathrm{R} / \mathrm{V}$ Investigator during CAPRICORN. Part I: Cloud occurrence and phase partitioning. J. Appl. Meteor. Climatol., 57, 1783-1803, https://doi.org/10.1175/ JAMC-D-17-0194.1.

Matus, A. V., and T. L. L'Ecuyer, 2017: The role of cloud phase in Earth's radiation budget. J. Geophys. Res. Atmos., 122, 2559-2578, https://doi.org/10.1002/2016JD025951.

McCoy, D. T., I. Tan, D. L. Hartmann, M. D. Zelinka, and T. Storelvmo, 2016: On the relationships among cloud cover, mixed-phase partitioning, and planetary albedo in GCMs. J. Adv. Model. Earth Syst., 8, 650-668, https://doi.org/10.1002/ 2015MS000589.

McFarquhar, G. M., G. Zhang, M. R. Poellot, G. L. Kok, R. McCoy, T. Tooman, A. Fridlind, and A. J. Heymsfield, 2007: Ice properties of single-layer stratocumulus during the Mixed-Phase Arctic Cloud Experiment: 1. Observations. J. Geophys. Res., 112, D24201, https://doi.org/10.1029/ 2007JD008633.

— Campaign (ISDAC): The impact of Arctic aerosols on clouds. Bull. Amer. Meteor. Soc., 92, 183-201, https://doi.org/10.1175/ 2010BAMS2935.1.

Meyers, M. P., P. J. DeMott, and W. R. Cotton, 1992: New primary ice-nucleation parameterizations in an explicit cloud model. J. Appl. Meteor., 31, 708-721, https://doi.org/10.1175/15200450(1992)031<0708:NPINPI>2.0.CO;2.

Mioche, G., and Coauthors, 2017: Vertical distribution of microphysical properties of Arctic springtime low-level mixed-phase clouds over the Greenland and Norwegian Seas. Atmos. Chem. Phys., 17, 12 845-12 869, https:// doi.org/10.5194/acp-17-12845-2017.

Morrison, H., and A. Gettelman, 2008: A new two-moment bulk stratiform cloud microphysics scheme in the Community Atmosphere Model, version 3 (CAM3). Part I: Description and numerical tests. J. Climate, 21, 3642-3659, https://doi.org/ 10.1175/2008JCLI2105.1.

—_ G. de Boer, G. Feingold, J. Harrington, M. D. Shupe, and K. Sulia, 2012: Resilience of persistent Arctic mixedphase clouds. Nat. Geosci., 5, 11-17, https://doi.org/10.1038/ ngeo1332.

Niedermeier, D., B. Ervens, T. Clauss, J. Voigtländer, H. Wex, S. Hartmann, and F. Stratmann, 2014: A computationally efficient description of heterogeneous freezing: A simplified version of the soccer ball model. Geophys. Res. Lett., 41, 736-741, https://doi.org/10.1002/2013GL058684. 
Niemand, M., and Coauthors, 2012: A particle-surface-area-based parameterization of immersion freezing on desert dust particles. J. Atmos. Sci., 69, 3077-3092, https://doi.org/10.1175/ JAS-D-11-0249.1.

Pinto, J. O., J. A. Curry, and J. M. Intrieri, 2001: Cloud-aerosol interactions during autumn over Beaufort Sea. J. Geophys. Res., 106, 15 077-15 097, https://doi.org/10.1029/2000JD900267.

Prenni, A. J., and Coauthors, 2007: Can ice-nucleating aerosol affect Arctic seasonal climate? Bull. Amer. Meteor. Soc., 88, 541-550, https://doi.org/10.1175/BAMS-88-4-541.

- , P. J. DeMott, D. C. Rogers, S. M. Kreidenweis, G. M. McFarquhar, G. Zhang, and M. D. Poellot, 2009: Ice nuclei characteristics from M-PACE and their relation to ice formation in clouds. Tellus, 61B, 436-448, https://doi.org/10.1111/ j.1600-0889.2009.00415.x.

Rangno, A. L., and P. V. Hobbs, 2001: Ice particles in stratiform clouds in the Arctic and possible mechanisms for the production of high ice concentrations. J. Geophys. Res., 106, 15 065-15 075, https://doi.org/10.1029/2000JD900286.

Roesler, E. L., D. J. Posselt, and R. B. Rood, 2017: Using large eddy simulations to reveal the size, strength, and phase of updraft and downdraft cores of an Arctic mixed-phase stratocumulus cloud. J. Geophys. Res. Atmos., 122, 4378-4400, https:// doi.org/10.1002/2016JD026055.

Rotstayn, L. D., B. F. Ryan, and J. J. Katzfey, 2000: A scheme for calculation of the liquid fraction in mixed-phase stratiform clouds in large-scale models. Mon. Wea. Rev., 128, 1070-1088, https:// doi.org/10.1175/1520-0493(2000)128<1070:ASFCOT>2.0.CO;2.

Savre, J., and A. M. L. Ekman, 2015a: Large-eddy simulation of three mixed-phase cloud events during ISDAC: Conditions for persistent heterogeneous ice formation. J. Geophys. Res. Atmos., 120, 7699-7725, https://doi.org/10.1002/ 2014JD023006.

—_, and ——, 2015b: A theory-based parameterization for heterogeneous ice nucleation and implications for the simulation of ice processes in atmospheric models. J. Geophys. Res. Atmos., 120, 4937-4961, https://doi.org/ 10.1002/2014JD023000.

Solomon, A., M. D. Shupe, P. O. G. Persson, and H. Morrison, 2011: Moisture and dynamical interactions maintaining decoupled Arctic mixed-phase stratocumulus in the presence of a humidity inversion. Atmos. Chem. Phys., 11, 10 127-10148, https://doi.org/10.5194/acp-11-10127-2011.

Tan, I., T. Storelvmo, and Y.-S. Choi, 2014: Spaceborne lidar observations of the ice-nucleating potential of dust, polluted dust, and smoke aerosols in mixed-phase clouds. J. Geophys. Res. Atmos., 119, 6653-6665, https://doi.org/ 10.1002/2013JD021333.

- — - and M. D. Zelinka, 2016: Observational constraints on mixed-phase clouds imply higher climate sensitivity. Science, 352, 224-227, https://doi.org/10.1126/science.aad5300.

Taylor, K., D. Williamson, and F. Zwiers, 2000: The sea surface temperature and sea ice concentration boundary conditions for AMIP II simulations. Lawrence Livermore National Laboratory PCMDI Rep. 60, 25 pp.

Thompson, G., P. R. Field, R. M. Rasmussen, and W. D. Hall, 2008: Explicit forecasts of winter precipitation using an improved bulk microphysics scheme. Part II: Implementation of a new snow parameterization. Mon. Wea. Rev., 136, 5095-5113, https://doi.org/10.1175/2008MWR2387.1.

Ullrich, R., and Coauthors, 2017: A new ice nucleation active site parameterization for desert dust and soot. J. Atmos. Sci., 74, 699-717, https://doi.org/10.1175/JAS-D-16-0074.1.

Vali, G., 2014: Interpretation of freezing nucleation experiments: Singular and stochastic; sites and surfaces. Atmos. Chem. Phys., 14, 5271-5294, https://doi.org/10.5194/acp-14-52712014.

- and J. R. Snider, 2015: Time-dependent freezing rate parcel model. Atmos. Chem. Phys., 15, 2071-2079, https://doi.org/ 10.5194/acp-15-2071-2015.

Vergara-Temprado, J., and Coauthors, 2018: Strong control of Southern Ocean cloud reflectivity by ice-nucleating particles. Proc. Natl. Acad. Sci. USA, 115, 2687-2692, https://doi.org/ 10.1073/pnas.1721627115.

von Schuckmann, K., and Coauthors, 2016: An imperative to monitor Earth's energy imbalance. Nat. Climate Change, 6, 138-144, https://doi.org/10.1038/nclimate2876.

Wang, Y., and X. Liu, 2014: Immersion freezing by natural dust based on a soccer ball model with the Community Atmospheric Model version 5: Climate effects. Environ. Res. Lett., 9, 124020, https://doi.org/10.1088/1748-9326/9/12/124020.

- — - C. Hoose, and B. Wang, 2014: Different contact angle distributions for heterogeneous ice nucleation in the Community Atmospheric Model version 5. Atmos. Chem. Phys., 14, 10 411-10 430, https://doi.org/10.5194/acp-14-10411-2014.

Welti, A., F. Lüönd, Z. A. Kanji, O. Stetzer, and U. Lohmann, 2012: Time dependence of immersion freezing: An experimental study on size selected kaolinite particles. Atmos. Chem. Phys., 12, 9893-9907, https://doi.org/10.5194/acp12-9893-2012.

Wilson, T. W., and Coauthors, 2015: A marine biogenic source of atmospheric ice-nucleating particles. Nature, 525, 234-238, https://doi.org/10.1038/nature14986.

Wolf, V., T. Kuhn, M. Milz, P. Voelger, M. Krämer, and C. Rolf, 2018: Arctic ice clouds over northern Sweden: Microphysical properties studied with the Balloon-Borne Ice Cloud particle Imager B-ICI. Atmos. Chem. Phys., 18, 17371-17386, https:// doi.org/10.5194/acp-18-17371-2018.

Yang, F., M. Ovchinnikov, and R. A. Shaw, 2013: Minimalist model of ice microphysics in mixed-phase stratiform clouds. Geophys. Res. Lett., 40, 3756-3760, https://doi.org/10.1002/grl.50700.

Zender, C. S., H. Bian, and D. Newman, 2003: Mineral dust entrainment and deposition (DEAD) model: Description and 1990s dust climatology. J. Geophys. Res., 108, 4416, https:// doi.org/10.1029/2002JD002775

Zhao, M., and Coauthors, 2018a: The GFDL global atmosphere and land model AM4.0/LM4.0: 1. Simulation characteristics with prescribed SSTs. J. Adv. Model. Earth Syst., 10, 691-734, https://doi.org/10.1002/2017MS001208.

, and Coauthors, 2018b: The GFDL global atmosphere and land model AM4.0/LM4.0: 2. Model description, sensitivity studies, and tuning strategies. J. Adv. Model. Earth Syst., 10, 735-769, https://doi.org/10.1002/2017MS001209. 